\title{
Recent Updates in the Formulation Strategies to Enhance the Bioavailability of Drugs Administered via Intranasal Route
}

\author{
Narendar Dudhipala ${ }^{1 *}$, Arjun Narala ${ }^{1}$ and Ramesh Bomma ${ }^{2}$ \\ ${ }^{1}$ Department of Pharmaceutics, Vaagdevi Institute of Pharmaceutical Sciences, Warangal, Telangana-506009, India \\ ${ }^{2} S R R$ Institute of Pharmaeutical Sciences, Karimnagar, Telangana, India
}

\begin{abstract}
Targeting drugs to the brain or Cerebrospinal fluid (CSF) is limited because of the physiological barriers like blood-brain barrier and blood-CSF barriers. Alternative non-invasive, patient compliant delivery routes like intranasal route was investigated by several research groups to target both small and large molecules. Several barriers that limit the bioavailability and research formulation strategies adopted by various research groups are discussed in brief in this review article.
\end{abstract}

Keywords: Brain; Cerebrospinal fluid; Intranasal; Formulation; Non-invasive

\section{Introduction}

Targeting drugs to the central nervous system via oral or IV route is a challenge because of the physiological barriers like Blood Brain and Blood cerebrospinal fluid (CSF) barrier. Intranasal (IN) route is devoid of the various barriers for delivery of drugs to CNS [1-16]. This route facilitates patent compliance, ease of administration, low dose requirement and minimal side effects [9,11-15,17-19]. The overall objective of the review is to provide the recent advances in the intranasal delivery of therapeutic agents to the brain and the CSF.

Intranasal delivery of drugs to the CNS will be delivered to the olfactory bulb and the brain via the olfactory and trigeminal components respectively. The transport of drugs will be further carried out across epithelial membrane barriers or to brain entry sites from nasal mucosa or from brain entry sites to other sites following a transcellular, paracellular or neuronal transport pathways.

Low membrane permeability across nasal mucosa is considered to be a major limiting factor for the absorption of polar drugs and peptides. The absorption of the drugs across the nasal epithelium is influenced by the physicochemical properties of the drug. Lipophilic drugs have a higher rate of absorption whereas various factors like molecular weight, membrane permeability, mucociliary clearance and enzymatic degradation influence the absorption of hydrophilic drugs.

In addition rapid mucociliary clearance also serves as a road block and confines the residence time of the drugs which in turn reduces the half-life of the intranasal formulations (liquid and powder dosage forms) to an order of 15-20 min [19,20]. Site of deposition either anterior or posterior area of the nasal region also influences the clearance of drugs. Drugs targeted to the anterior part of the nasal cavity may be subjected to minimal nasal clearance and promote absorption compared to the deposition in further back region. Various enzymes present in the mucosal region may also limit the bioavailability of the drugs. In the current various formulation strategies to enhance the bioavailability of drugs administered via intranasal route is discussed.

\section{Formulation Strategies to Enhance Intranasal Drug Delivery}

To overcome the barriers that limit the bioavailability of drugs administered via intranasal route, various formulation approaches such as enhancing the drug permeability across the nasal epithelium, minimizing clearance from the nasal passage and protecting drugs from degradation may enhance the capabilities of intranasal drug delivery to CNS.

\section{Alteration of Membrane Permeability Using Permeation Enhancers}

The poor permeability of the nasal mucosa limits the permeability of the drugs across nasal mucosa and it could be enhanced by improving permeability of drugs across the mucosal epithelium. This enhancement in permeation aids in the enhancement of extracellular transport to the CNS along olfactory and trigeminal nerve. Tight junctions present in the epithelia also limit the permeability to a certain extent and limits the bioavailability of the drug molecules. The use of permeation enhancers like surfactants, tight junction modifiers, bile salts, lipids and polymers may modify the permeability of the drugs across the nasal mucosa.

Cationic polymers like chitosan when co-administered may enhance the absorption across the nasal mucosa. Vaka et al. investigated the efficacy of chitosan to facilitate brain bioavailability of intranasally administered nerve growth factor (NGF) and reported that use of chitosan enhanced the permeation of NGF across the olfactory epithelium by 5 fold compared to the control during the in vitro permeation studies $[21,22]$. A comparative evaluation of the intranasal administration of NGF with chitosan and without chitosan was also evaluated in Sprague Dawley rats and it is very clearly evident form the PK results that $\mathrm{C}_{\max }$ of NGF in brain was enhanced by $\sim 14$ fold upon use of chitosan compared to its control.

Manda et al., investigated the ability of the chitosan to enhance the permeation of Cefotaxime and reported that $0.25 \% \mathrm{w} / \mathrm{v}$ chitosan across the olfactory epithelium was enhanced about $\sim 2$ fold in the 2 hours of

${ }^{*}$ Corresponding author: Narendar Dudhipala, Associate Professor, Vaagdev Institute of Pharmaceutical Sciences, Warangal, Telangana-506009, India, Tel: 8099722523; E-mail: dnrlu14@gmail.com

Received June 30, 2016; Accepted June 30, 2016; Published July 07, 2016

Citation: Dudhipala N, Narala A, Bomma R (2016) Recent Updates in the Formulation Strategies to Enhance the Bioavailability of Drugs Administered via Intranasal Route. J Bioequiv Availab 8: 204-207. doi:10.4172/jbb.1000295

Copyright: (C) 2016 Dudhipala N, et al. This is an open-access article distributed under the terms of the Creative Commons Attribution License, which permits unrestricted use, distribution, and reproduction in any medium, provided the original author and source are credited. 
time compared to control $[9,23]$. In vivo studies were carried out in Sprague Dawley rats by intravenous and intranasal administration of cefotaxime. The MIC levels were attained within a short time span and were maintained for a considerable period of time. The time required to attain maximum concentration in case of intranasal $\left(\mathrm{t}_{\max }=30 \mathrm{~min}\right)$ was rapid compared to intravenous $\left(\mathrm{t}_{\max }=180 \mathrm{~min}\right)$ and the absolute bioavailability following intranasal administration was about $86 \%$.

Vaka et al. investigated the ability of peppermint oil to enhance the permeation of NGF across the olfactory mucosa and reported that peppermint oil at concentrations of $0.05,0.1$ and $0.5 \% \mathrm{v} / \mathrm{v}$ enhanced the in vitro transport of NGF by 5, 7 and 8 fold, respectively. In vivo studies employing brain microdialysis in rats demonstrated that intranasal administration of NGF formulation with $0.5 \%$ peppermint oil enhanced the bioavailability by $\sim 8$ fold compared to rats administered with NGF alone [24-26]. The bioavailability of NGF in the brain could be enhanced by intranasal administration of peppermint oil.

The change in osmolarity of the formulation may enhance the intercellular or extracellular transport mechanism to the CNS region. A change in the amount of vasoactive intestinal peptide with a change in osmolarity of the formulation was reported [27]. Ionization state of the drug and $\mathrm{pH}$ of the formulation may also affect the permeability of the drugs when administered intranasally. Sulphonamides with different fractions of ionization when administered intranasally were found to have differences in permeability to the CSF [28].

\section{Nanoparticular Delivery System}

Mucociliary clearance reduces the contact time of drugs with the nasal epithelia and rapidly removes drugs from the delivery site. Use of nanoparticles, mucoadhesive agents, absorption enhancers, surfactants, lipid emulsions, vasoconstrictors and efflux transporter inhibitors are some of the potential approaches to reduce the clearance and enhance the residence time [29-37].

Nanoparticulate drug delivery systems have the capability to enhance the bioavailability of drugs upon intranasal administration compared to drug solutions [38-43]. These formulations were reported to increase the residence time in the nasal cavity and prevent the effect of enzymatic degradation on these drugs [41]. Insulin nanoparticles were also reported to reduce the plasma glucose levels when compared to the insulin solution $[38,44,45]$. The better efficacy of the nanoparticulate formulation was due to the strengthened contact of the nanoparticles with the epithelium.

Nanoparticle with modified surface properties may be used for mucosal binding, reduce clearance and enhance delivery to CNS. In a study by Kravtzoff et al. it was reported that the mean residence halflife was extended to $2.3 \mathrm{~h}$ in the human nasal cavity when compared to that of the residence half-life $(15-30 \mathrm{~min})$ of solution upon the use of cationic Biovector ${ }^{\mathrm{TM}}$ nanoparticle system [46,47]. The levels of fluorescent markers in various regions of brain was enhanced when Ulex europeus agglutinin I and wheat germ agglutinin conjugated horseradish peroxidase upon conjugation with PEG-PLA nanoparticles compared to unmodified nanoparticles. Use of vasoconstrictors to reduce the clearance in to the blood and treatment with inhibitors of the efflux transporters reduces the clearance in to the blood and enhances the drug to the CNS. Vaka et al. investigated the capabilities of carnosic acid nanaoparticular systems to enhance the in vivo efficacy of carnosic acid and enhance the neurotropin expression in the brain [48-50]. It was reported that intranasal administration of carnosic acid nanoparticles resulted in comparable levels of endogenous neurotrophins level in the brain that was equivalent to the four, once a day intranasal administration of solution in rats and demonstrated the fact that nanoparticulate drug delivery system for intranasal administration of carnosic acid reduces the number of administrations to elicit the required pharmacological activity.

\section{Polymeric Delivery Systems}

Polymers with high molecular weight and flexible chains are used as bioadhesives, they have the capability to interact with mucin by forming hydrogen, electrostatic, hydrophobic or van der waals interactions. Thermoreversible polymers have the capability to exist in both sol and gel form at low and high temperatures respectively, and are referred as in situ gels. Because of its dual nature, it can be used as drug carrier for intranasal delivery where the therapeutics will be administered in the solution form at low temperatures and turns to semi-solid gels with change in physiological temperature. Polymeric vehicles like Kolliphor P 407 are reported to deliver the drugs at therapeutic concentrations, prolong the release of therapeutic agents and protect the therapeutic agents from enzymatic degradation. Perez et al. successfully delivered naked siRNA and poloxamer polymers, as in situ mucoadhesive gels to brain via olfactory epithelium [51]. Chen et al. could successfully enhance effect of radix bulperi and retain its effect for a longer time in CSF following administration of temperature sensitive in situ gels [52]. Manda et al. investigated the ability of delivering ziconotide via intranasal route. Ziconotide when delivered using poloxomer as a vehicle could not only attain therapeutic concentration rapidly but also prolong the release of ziconotide, maintain therapeutic levels in CSF for a longer period of time compared to solution and reduce the frequency of administration [53].

\section{Conclusion}

Intranasal delivery appears to be a promising route for targeting drugs either to brain and CSF. This route will be very effective in treating various CNS disorders and various formulation strategies have already demonstrated the potential to enhance and prolong the release of therapeutic agents. It will be of great interest to the research community to explore further advances in targeting drugs to CNS via non-invasive patient compatible intranasal route for disease conditions that need a rapid onset of action.

\section{References}

1. Landsteiner K, Levaditi C (1910) Experimental study of acute poliomyelitis (Heine- Medin disease), Paris.

2. Flexner S (1912) THe mode of infection in epidemic poliomyelitis. Journal of the American Medical Association 59: 1371-1372.

3. Fairbrother RW, Hurst EW (1930) The pathogenesis of, and propagation of the virus in, experimental poliomyelitis. The Journal of Pathology and Bacteriology 33: $17-45$

4. Anand Kumar TC, David GF, Kumar K, Umberkoman B, Krishnamomorthy MS (1976) International Symposium on Neuroendocrine Regulation of Fertility, Neuroendocrine regulation of fertility: a potential new approach to human fertility regulation by interfering with neuroendocrine pathways. In: Basel KS (ed.). New York.

5. Shipley MT (1985) Transport of molecules from nose to brain: transneuronal anterograde and retrograde labeling in the rat olfactory system by wheat germ agglutinin-horseradish peroxidase applied to the nasal epithelium. Brain Research Bulletin 15: 129-142.

6. Thorne RG, Hanson LR, Ross TM, Tung D, Frey WH (2008) Delivery of interferon- $\beta$ to the monkey nervous system following intranasal administration. Neuroscience 152: 785-797.

7. Dhanda DS, Leopold D, Kompella UB (2005) Approaches for drug deposition in the human olfactory epithelium. Drug Deliv 5: 64-72. 
Citation: Dudhipala N, Narala A, Bomma R (2016) Recent Updates in the Formulation Strategies to Enhance the Bioavailability of Drugs Administered via Intranasal Route. J Bioequiv Availab 8: 204-207. doi:10.4172/jbb.1000295

8. Frey WH (2002) Intranasal delivery: bypassing the blood-brain barrier to deliver therapeutic agents to the brain and spinal cord. Drug Deliv Technol 2: 46-49.

9. Manda P, Hargett JK, Vaka SR, Repka MA, Murthy SN (2011) Delivery of cefotaxime to the brain via intranasal administration. Drug Dev Ind Pharm 37 1306-1310.

10. Li Y, Field PM, Raisman G (2005) Olfactory ensheathing cells and olfactory nerve fibroblasts maintain continuous open channels for regrowth of olfactory nerve fibres. Glia 52: 245-251.

11. Birkhoff M, Leitz M, Marx D (2009) Advantages of intranasal vaccination and considerations on device selection. Indian J Pharm Sci 71: 729-731.

12. Zaki NM, Awad GA, Mortada ND, Abd Elhady SS (2007) Enhanced bioavailability of metoclopramide $\mathrm{HCl}$ by intranasal administration of a mucoadhesive in situ gel with modulated rheological and mucociliary transport properties. Eur $J$ Pharm Sci 32: 296-307.

13. Thorne RG, Pronk GJ, Padmanabhan V, Frey WH 2nd (2004) Delivery of insulin-like growth factor-I to the rat brain and spinal cord along olfactory and trigeminal pathways following intranasal administration. Neuroscience 127: 481-496.

14. Knoester PD, Jonker DM, Van Der Hoeven RT, Vermeij TA, Edelbroek PM, et al. (2002) Pharmacokinetics and pharmacodynamics of midazolam administered as a concentrated intranasal spray. A study in healthy volunteers. Br J Clin Pharmacol 53: 501-507.

15. Woodley $\mathrm{J}$ (2001) Bioadhesion: new possibilities for drug administration? Clin Pharmacokinet 40: 77-84

16. Manda P, Sammeta SM, Repka MA, Murthy SN (2012) lontophoresis across the proximal nail fold to target drugs to the nail matrix. J Pharm Sci 101: 2392 2397.

17. Ying W (2008) The nose may help the brain: intranasal drug delivery for treating neurological diseases. Future Neurology 3: 1-4.

18. Manda P, Angamuthu M, Hiremath SR, Raman V, Murthy SN (2014) lontophoretic drug delivery for the treatment of scars. J Pharm Sci 103: 1638-1642.

19. Juluri A, Popescu C, Zhou L, Murthy RN, Gowda VK, et al. (2016) Taste Masking of Griseofulvin and Caffeine Anhydrous Using Kleptose Linecaps DE17 by Hot Melt Extrusion. AAPS PharmSciTech 17: 99-105.

20. Hilger P, Adams G, Boies L, Hilger P (1989) Applied anatomy and physiology of the nose, GL Adams, LR Boies, and PA Hilger, Philadelphia: WB Saunders, pp: 177-195.

21. Vaka SR, Sammeta SM, Day LB, Murthy SN (2009) Delivery of nerve growth factor to brain via intranasal administration and enhancement of brain uptake. J Pharm Sci 98: 3640-3646.

22. Juluri A, Modepalli N, Jo S, Repka MA, Shivakumar HN, et al. (2013) Minimally invasive transdermal delivery of iron-dextran. J Pharm Sci 102: 987-993.

23. Kushwaha A, Jacob M, Shiva Kumar HN, Hiremath S, Aradhya S, et al. (2015) Trans-ungual delivery of itraconazole hydrochloride by iontophoresis. Drug Dev Ind Pharm 41: 1089-1094.

24. Loria MJ, White SW, Robbins SA, Salmeto AL, Hymel KA (2013) Brain-derived neurotrophic factor response in vulnerable and resilient genetic lines in the chick anxiety-depression model. Behav Brain Res 245: 29-33.

25. Vaka SR, Murthy SN (2010) Enhancement of nose-brain delivery of therapeutic agents for treating neurodegenerative diseases using peppermint oil. Pharmazie 65: 690-692.

26. Kushwaha A, Murthy RN, Murthy SN, Elkeeb R, Hui Xm, et al. (2015) Emerging therapies for the treatment of ungual onychomycosis. Drug Dev Ind Pharm 41 : $1575-1581$.

27. Dufes C, Olivier JC, Gaillard F, Gaillard A, Couet W, et al. (2003) Brain delivery of vasoactive intestinal peptide (VIP) following nasal administration to rats. Int J Pharm 255: 87-97.

28. Sakane T, Akizuki M, Yamashita S, Sezaki H, Nadai T (1994) Direct drug transport from the rat nasal cavity to the cerebrospinal fluid: the relation to the dissociation of the drug. J Pharm Pharmacol 46: 378-379.
29. Pisal SS, Paradkar AR, Mahadik KR, Kadam SS (2004) Pluronic gels for nasa delivery of Vitamin B12. Part I: preformulation study. Int J Pharm 270: 37-45

30. Tas C, Ozkan CK, Savaser A, Ozkan Y, Tasdemir U, et al. (2006) Nasa absorption of metoclopramide from different Carbopol 981 based formulations: In vitro, ex vivo and in vivo evaluation. Eur J Pharm Biopharm 64: 246-254.

31. Sandri G, Rossi S, Ferrari F, Bonferoni MC, Muzzarelli C, et al. (2004) Assessment of chitosan derivatives as buccal and vaginal penetration enhancers. Eur J Pharm Sci 21: 351-359.

32. Bilensoy E, Rouf MA, Vural I, Šen M, Hincal AA (2006) Mucoadhesive thermosensitive, prolonged-release vaginal gel for clotrimazole: ß-cyclodextrin complex, AAPS PharmSciTech 7: E54-E60.

33. Lin H, Gebhardt M, Bian S, Kwon KA, Shim CK, et al. (2007) Enhancing effect of surfactants on fexofenadine. $\mathrm{HCl}$ transport across the human nasal epithelial cell monolayer. Int J Pharm 330: 23-31.

34. Mitra R, Pezron I, Chu WA, Mitra AK (2000) Lipid emulsions as vehicles for enhanced nasal delivery of insulin. Int J Pharm 205: 127-134.

35. Yang Y, Manda P, Pavurala N, Khan MA, Krishnaiah YS (2015) Development and validation of in vitro-in vivo correlation (IVIVC) for estradiol transderma drug delivery systems. J Control Release 210: 58-66.

36. Xu X, Al-Ghabeish M, Rahman Z, Krishnaiah YS, Yerlikaya F, et al. (2015) Formulation and process factors influencing product quality and in vitro performance of ophthalmic ointments. Int J Pharm 493: 412-425.

37. Juluri A, Peddikotla P, Repka MA, Murthy SN (2013) Transdermal iontophoretic delivery of propofol: a general anaesthetic in the form of its phosphate salt. $J$ Pharm Sci 102: 500-507.

38. Fernández-Urrusuno R, Calvo $P$, Remuñán-López C, Vila-Jato JL, Alonso MJ (1999) Enhancement of nasal absorption of insulin using chitosan nanoparticles. Pharm Res 16: 1576-1581.

39. Betbeder D, Spérandio S, Latapie JP, de Nadaí J, Etienne A, et al. (2000) Biovector $^{\text {Tw }}$ nanoparticles improve antinociceptive efficacy of nasal morphine. Pharm Res 17: 743-748.

40. Janes K, Calvo P, Alonso M (2001) Polysaccharide colloidal particles as delivery systems for macromolecules. Adv Drug Deliv Rev 47: 83-97.

41. Vila A, Sanchez A, Tobio M, Calvo P, Alonso M (2002) Design of biodegradable particles for protein delivery, J Control Release 78: 15-24.

42. Nagamoto T, Hattori Y, Takayama K, Maitani Y (2004) Novel chitosan particles and chitosan-coated emulsions inducing immune response via intranasal vaccine delivery. Pharm Res 2: 671-674

43. Popescu C, Manda P, Juluri A, Janga KY, Cidda M, et al. (2015) Enhanced dissolution efficiency of zaleplon solid dispersions via modified ß-cyclodextrin molecular inclusion complexes. J Pharm Pharm Sci 1: 12-21.

44. Juluri A, Murthy SN (2014) Transdermal iontophoretic delivery of a liquid lipophilic drug by complexation with an anionic cyclodextrin. J Control Release 189: 11-18.

45. Kushwaha A, Shivakumar HN, Murthy SN (2016) lontophoresis for drug delivery into the nail apparatus: exploring hyponychium as the site of delivery. Drug Dev Ind Pharm 19: 1-15.

46. Kravtzoff R, Fisher A, de Miguel I, Perkins A, Major M, et al. (1998) Nasal residence time evaluation of cationic Biovector ${ }^{\mathrm{TM}}$ in human volunteers. In: Proc Int Symp Control Rel Bioact Mater, pp: 818-819.

47. Illum L (2004) Is nose-to-brain transport of drugs in man a reality? J Pharm Pharmacol 56: 3-17.

48. Vaka SR, Shivakumar HN, Repka MA, Murthy SN (2013) Formulation and evaluation of carnosic acid nanoparticulate system for upregulation of neurotrophins in the brain upon intranasal administration. J Drug Target 21: 44-53.

49. Köllmer M, Popescu C, Manda P, Zhou L, Gemeinhart RA (2013) Stability of benzocaine formulated in commercial oral disintegrating tablet platforms. AAPS PharmSciTech 14: 1333-1340.

50. Shivakumar HN, Juluri A, Desai BG, Murthy SN (2012) Ungual and transungual drug delivery. Drug Dev Ind Pharm 38: 901-911. 
Citation: Dudhipala N, Narala A, Bomma R (2016) Recent Updates in the Formulation Strategies to Enhance the Bioavailability of Drugs Administered via Intranasal Route. J Bioequiv Availab 8: 204-207. doi:10.4172/jbb.1000295

51. Perez AP, Mundiña-Weilenmann C, Romero EL, Morilla MJ (2012) Increased brain radioactivity by intranasal P-labeled siRNA dendriplexes within in situforming mucoadhesive gels. Int J Nanomedicine 7: 1373-1385.

52. Chen E, Chen J, Cao SL, Zhang QZ, Jiang XG (2010) Preparation of nasal temperature-sensitive in situ gel of Radix Bupleuri and evaluation of the febrile response mechanism. Drug Dev Ind Pharm 36: 490-496.
53. Manda P, Kushwaha AS, Kundu S, Shivakumar HN, Jo SB, et al. (2016) Delivery of ziconotide to cerebrospinal fluid via intranasal pathway for the treatment of chronic pain. J Control Release 224: 69-76. 